\title{
Parental awareness of schoolbag carriage: A comparative study of Irish and United States parents
}

\author{
Sara Dockrell ${ }^{\mathrm{a}, *}$, Karen Jacobs ${ }^{\mathrm{b}}$, Julie Byrne ${ }^{\mathrm{a}}$, Emma Gleeson $^{\mathrm{a}}$, Sinead Kelly ${ }^{\mathrm{a}}$, Caitriona Moore ${ }^{\mathrm{a}}$, \\ Eimear O’Meara ${ }^{\mathrm{a}}$, Dagny Barclay ${ }^{\mathrm{b}}$, Sabrina Rodriguez ${ }^{\mathrm{b}}$, David Kang ${ }^{\mathrm{b}}$, Ciaran Simms ${ }^{\mathrm{c}}$ \\ and Catherine Blake ${ }^{\mathrm{d}}$ \\ ${ }^{a}$ Discipline of Physiotherapy, School of Medicine, Trinity College, Dublin, Ireland \\ ${ }^{\mathrm{b}}$ Department of Occupational Therapy, Boston College of Health \& Rehabilitation Sciences: \\ Sargent College, Boston University, Boston, MA, USA \\ ${ }^{\mathrm{c}}$ Mechanical and Manufacturing Engineering, Trinity College, Dublin, Ireland \\ ${ }^{\mathrm{d}}$ School of Public Health, Physiotherapy and Sports Science, Health Sciences Centre, \\ University College Dublin, Belfield, Dublin, Ireland
}

Received 28 July 2017

Accepted 16 August 2017

\begin{abstract}
.
BACKGROUND: Given the global nature of schoolbag carriage, there has been extensive research on schoolbag weight and use with resultant guidance on many aspects of carrying a schoolbag. However, there is limited evidence of knowledge translation or parents' awareness of schoolbag carriage.

OBJECTIVE: This study investigated parental awareness of factors related to schoolbag carriage.

METHOD: A cross-sectional survey using an anonymous 30-item questionnaire and purposive sampling was used. Questionnaires were distributed to parents of primary school children through the schools. Descriptive statistics of frequencies and percentages were used and associations were tested using Chi-square analysis in SPSS v23.

RESULTS: A total of 700 parents in Ireland (Ire) and the United States (US) participated in the study ( $n=444$ [Ire] and $n=256$ [US]). Generally, parents had satisfactory awareness of appropriate schoolbag type and carriage. The majority of children owned a backpack (89.9\% [Ire] vs. 93.7\% [US]), although fewer parents considered this to be the most suitable bag for their child (69.6\% [Ire] vs. $88.2 \%$ [US]). More Irish parents $(29.2 \%)$ favoured a wheeled schoolbag compared to US parents $(6.2 \%)(p<0.001)$. The majority (70.8\% [Ire] vs. 55.7\% [US]) wanted more information. The preferred platforms for receiving information were a handout (78.1\% [Ire] vs. 71.6\% [US]) and on-line (44.6\% [Ire] vs. 53.9\% [US]).

CONCLUSIONS: Despite gaps identified, parents had good awareness of factors relating to schoolbag carriage, but this study shows that they would like more information. The preferred platform for knowledge translation was a handout. Parents are the best advocates for safety promotion and represent the group most likely to improve schoolbag carriage among children.
\end{abstract}

Keywords: Schoolbag, parents, awareness

\section{Introduction}

Carrying a schoolbag is a worldwide activity that is undertaken by children from the age of

*Address for correspondence: Sara Dockrell, PhD, MA, MEd, Discipline of Physiotherapy, School of Medicine, Trinity College, Dublin 2, Ireland. Tel.: +353 18962126; Fax: +353 14531915; E-mail: sara.dockrell@tcd.ie. approximately four to 18 years. Given the ubiquitous nature of the activity, there has been extensive research on schoolbag use with resultant guidance on many aspects of carrying a schoolbag such as the optimum type of bag, schoolbag features, method of carriage, and the weight of the schoolbag. In Europe and Australia the guidelines state that children can carry a schoolbag that weighs up to $10 \%$ of their 
body weight (BW) [1-5]. In the United States, the American Occupational Therapy Association (AOTA) (2014) [6], recommends $10 \% \mathrm{BW}$ as the upper limit, the American Physical Therapy Association (APTA) (2014) [7], recommends 10-15\% BW and the American Academy of Pediatrics (AAP) (2014) [8], recommends 10-20\% BW.

From a review of the literature, it appears that children and their parents do not generally adhere to the advice of health care professionals on guidance related to schoolbag use. Regardless of the lack of consensus, and the use of unsubstantiated schoolbag weight limits that are based on a child's body weight, guideline load limits still exist $[9,10]$. But extensive research has demonstrated poor compliance with specific schoolbag weight guidelines [3, 11-13]. However adherence implies the person's agreement and willingness to follow a recommended plan $[14,15]$. In order to adhere or be compliant, a person needs an understanding about what it is they are expected to be compliant with [16] and have the ability to be compliant [17]. In the case of schoolbag carriage, although there is a large body of research on the compliance or adherence of children to the guidelines, there is limited research to validate that children or their parents have ever received information or advice about schoolbags [18] and are therefore not aware of schoolbag issues [19].

Only a small number of studies have investigated parents' awareness of schoolbag carriage [19-23]. Parents' awareness of recommended schoolbag weight has been reported to be low $[20,21]$ with less than half aware of the recommended weight limit (48.4\% and $45.5 \%$ respectively). In contrast, it was found that over two-thirds $(67.6 \%)$ of parents were aware of schoolbag load limits [23] and Magrabi et al (2015), reported that $83.9 \%$ of parents stated that the ideal schoolbag weight should be $<15 \%$ of the child's BW [22]. However, in all studies a binary response (Yes/No) was required and hence parents had a 50/50 chance of giving the correct answer. Gender differences in levels of awareness were also reported with fathers being more aware than mothers of the recommended weight limit [20, 21].

A proposed strategy to control schoolbag weight could be the involvement of parents to monitor the contents of their child's schoolbag, as it has been found that parental awareness is associated with schoolbag weight [21]. Yet, it has been reported that many parents never check their child's bag weight [19, 22]. Forjuoh et al (2003), also reported that significantly heavier schoolbags were carried by children whose bags had never been checked [19]. However, a limitation of their study is the data collected was based on the children's self-reports.

The level of parental awareness of the type of bag has been shown to be satisfactory with the majority of parents choosing a backpack [21, 22]. It has also been found, with one exception (Magrabi et al. 2015), that parents are aware of the optimum method of carriage [20, 21, 23], with fathers significantly more knowledgeable about the method of schoolbag carriage than mothers $[20,21]$. Furthermore, it was reported that parents with lower educational levels had lower awareness of optimal schoolbag use [21]. Poor awareness of the correct size of a schoolbag has been reported $[20,22]$ with only $10.9 \%$ and $10.4 \%$ respectively of parents being aware that the schoolbag should fit the child.

Knowledge translation has been defined as 'ensuring that stakeholders are aware of and use research evidence to inform their health and healthcare decision-making' [24, p.2] but there is limited evidence of this for schoolbag carriage. It seems reasonable that advice on best practice for schoolbag carriage should be provided to parents, children and teachers. Carrying a well-designed and correctlyfitted backpack over both shoulders has been accepted by the research community and professional organizations as the optimum method of schoolbag carriage in the real-world setting. Therefore, the focus of research on schoolbag characteristics and carriage should be on what is required to improve parental adherence to schoolbag-related advice, given that parents are the best-placed advocates for their childrens' health. The dearth of research in this area means that it has not been established what parents already know about schoolbag carriage. Nor have the platforms for knowledge translation to parents been identified. The objectives of this study were to establish the level of parental awareness about: (i) schoolbag type and design features; (ii) schoolbag use; and (iii) the effects of wearing a schoolbag. Further objectives were to: (iv) establish the sources of acquired information if appropriate and (v) establish the preferred platforms of the parents for receiving information about schoolbag use.

\section{Method}

\subsection{Research design}

A cross-sectional, anonymous questionnaire survey was used. 


\subsection{Participants}

Purposive sampling of primary schools with varying school size, type, geographical and socioeconomic catchment areas was used for the study. Due to the large number of primary school children in Ireland and the US, it was not possible to obtain a completely representative sample. Given the lack of prior data on parental knowledge to guide sample size requirements, a conservative approach was taken (based on an expected 50\% population knowledge of schoolbag guidelines, with $95 \% \mathrm{CI}$, margin of error $0.05 \%$ ) [25]. A total sample of 377 parents was projected from the target population. Criteria for inclusion were parents of junior infant, second class, and fifth class students attending the selected primary schools in Ireland and elementary schools, kindergarten to fifth grade in the US.

\subsection{Procedure}

School principals were approached by email or telephone to enquire if the study could be conducted on the parents of children in their school. Once permission was obtained, an information pack was delivered to the principals informing them of the study objectives, together with packs for circulation to the potential participants. School children were asked to take home the pack which included an invitation letter, a participant information leaflet and the questionnaire. Parents were asked to return the completed questionnaire to the school via their children and questionnaires were placed in a box in the classroom. Completed questionnaires were then collected by the researchers. In the US study, parents were also given the option of completing the questionnaire on-line.

\subsection{Ethical considerations}

The study was approved by the School of Medicine Research Ethics Committee, Trinity College Dublin and the Boston University Institutional Review Board (IRB). Return of the completed questionnaire was considered as consent.

\subsection{Measures}

A 30-item questionnaire, developed by experienced researchers and based on the relevant literature to ensure content validity was used in the study. The questions were predominantly multiple-choice closed $(n=28)$, and sought information on the child $(n=2)$, schoolbag design, type, weight, method of carriage $(n=11)$, effects of wearing a schoolbag $(n=4)$, schoolbag purchase $(n=2)$, transport to/from school $(n=1)$ and the availability and demand for information $(n=4)$. Parental demographic details were gathered to verify the sample was representative $(n=6)$.

\subsubsection{Reliability and validity}

A pilot study was conducted on a convenience sample of five $(n=5)$ parents of primary school children to ensure face validity, readability, clarity and length of time to complete the questionnaire. Minor amendments were made following the pilot study and a 5-10 minute period was identified as sufficient for questionnaire completion.

Test-retest reliability was assessed using a separate convenience sample of parents $(n=10)$. Parents completed the questionnaire on two occasions with a one-week interval. Excellent reliability (94.3\% agreement) was demonstrated. These parents were excluded from the main study.

\subsection{Data management and analysis}

Questionnaires were checked for completeness. A double entry data procedure was used and the accuracy of the data was further verified using random checks and frequency analysis [26]. Statistical analysis was performed using Statistical Package for the Social Sciences (SPSS v.23) (SPSS Inc., Chicago, Illinois, USA). Descriptive analysis including percentages (95\% confidence intervals) was used. Chi-squared tests were used to test for associations between variables. Comparisons were made between the responses of the Irish parents (IRE) followed by those of the American (US) parents in brackets [ ]. The strength of linear associations was assessed using Pearson's correlation. Statistical significance of $p<0.05$ was assumed for all tests.

\section{Results}

A total of 700 questionnaires were completed by Irish $(n=444)$ and United States $(n=256)$ parents representing response rates of $64.6 \%$ and $25.6 \%$ respectively.

\subsection{Participant demographics}

The sample was predominantly female aged 30-49 years, married, of white ethnicity. The majority 
Table 1

Demographic characteristics of parents

\begin{tabular}{|c|c|c|}
\hline \multirow[t]{2}{*}{ Characteristics } & \multicolumn{2}{|c|}{$\%$} \\
\hline & $\operatorname{IRE}(n=444)$ & US $(n=256)$ \\
\hline \multicolumn{3}{|l|}{ Gender } \\
\hline Female & 88.1 & 88.9 \\
\hline Male & 10.8 & 10.7 \\
\hline Did not answer & 1.1 & 0.4 \\
\hline \multicolumn{3}{|l|}{ Age (years) } \\
\hline$<30$ & 7.7 & 8.7 \\
\hline $30-39$ & 42.4 & 39.4 \\
\hline $40-49$ & 47.2 & 43.7 \\
\hline $50-59$ & 2.5 & 7.5 \\
\hline$>60$ & 0.2 & 0.8 \\
\hline \multicolumn{3}{|l|}{ Education } \\
\hline Primary/Elementary & 3.8 & 0.4 \\
\hline Secondary/High & 28.9 & 13.1 \\
\hline Third level*/University & 47.9 & 55.2 \\
\hline Postgraduate & 19.4 & 31.3 \\
\hline \multicolumn{3}{|l|}{ Marital Status } \\
\hline Single & 17.2 & 15.1 \\
\hline Married & 77.6 & 76.5 \\
\hline Separated & 3.2 & 0.8 \\
\hline Divorced & 1.5 & 6.8 \\
\hline Widowed & 0.5 & 0.8 \\
\hline \multicolumn{3}{|l|}{ Ethnicity } \\
\hline White & 93.0 & 80.6 \\
\hline Black & 2.3 & 6.5 \\
\hline Asian & 2.9 & 4.9 \\
\hline Am Indian/Alaska & 0.0 & 1.2 \\
\hline Other & 1.8 & 6.9 \\
\hline \multicolumn{3}{|l|}{ Spoken language } \\
\hline English & 81.4 & 93.3 \\
\hline Other & 7.1 & 6.8 \\
\hline Bi-lingual & 11.5 & 0.0 \\
\hline
\end{tabular}

*Third level education in Ireland is provided by the university sector, the technological sector, colleges of education and independent private colleges.

of parents had a third level/university education (Table 1).

\subsection{Schoolbag type and design features}

The backpack was the most commonly used schoolbag, although parental awareness was lower regarding its suitability. There were significant differences in opinion of suitability between Irish and United States parents (Table 2). A parent was involved in choosing the schoolbag in $82.4 \%$ (Ire) and $80.8 \%$ (US) of the responses. When Irish mothers were involved, children were significantly more likely to own a backpack $(p=0.048)$. A linear effect was also detected, with the frequency of wheeled bags decreasing with increasing child age $(r=-0.310$, $p<0.01$ ). Younger children and youngest siblings were significantly more likely to own a wheeled bag ( $p=0.01$ and $p=0.01$ respectively) and oldest siblings a backpack $(p=0.01)$.

The presence of schoolbag features and parental knowledge regarding the importance of these features were satisfactory. A hip strap was absent from most schoolbags with only a small proportion rating this feature as important (Table 3). In terms of design features, reflectors were considered important by $82.1 \%$ of Irish and $62.3 \%$ of United States parents. When asked to identify the appropriate schoolbag size, $86.4 \%$ of Irish and $91 \%$ of United States parents choose one/both of the correct images on the survey, indicating adequate knowledge regarding appropriate schoolbag fit. There were five images to choose from, two of which were in keeping with advice that the bag should be a suitable size to be worn in the centre of back [23] and should fit close to the back [7].

\subsection{Schoolbag use}

The majority of parents were aware of the correct method of schoolbag carriage, although significantly more United States parents were correct compared to the Irish $(p<0.001)$. More Irish parents favoured wheeled schoolbags than United States parents $(p<0.05)$ (Table 4).

Europe has a guideline load limit of $<10 \% \mathrm{BW}$ and in the United States it varies between 10-20\% BW. Hence, there was a significant difference in the awareness of the guideline $(p<0.001)$ between the Irish and United States parents (Table 4). The majority

Table 2

Comparison of schoolbag owned and schoolbag considered most suitable among Irish $(n=444)$ and United States $(n=256)$ parents

\begin{tabular}{|c|c|c|c|c|c|c|c|c|}
\hline \multirow[t]{2}{*}{ Bag type } & & \multicolumn{3}{|c|}{ Schoolbag owned } & & \multicolumn{3}{|c|}{ Most suitable schoolbag } \\
\hline & & $\%$ & $x^{2}$ & $p$ & & $\%$ & $x^{2}$ & $p$ \\
\hline \multirow[t]{2}{*}{ Backpack } & IRE & 89.9 & 2.945 & 0.086 & IRE & 69.6 & 31.114 & $<0.00$ \\
\hline & US & 93.7 & & & US & 88.2 & & \\
\hline \multirow[t]{2}{*}{ With wheels } & IRE & 9.4 & 10.493 & $<0.01$ & IRE & 29.2 & 52.089 & $<0.001$ \\
\hline & US & 2.9 & & & US & 6.2 & & \\
\hline \multirow[t]{2}{*}{ Other } & IRE & 0.7 & 7.125 & $<0.01$ & IRE & 1.2 & 11.498 & $<0.00$ \\
\hline & US & 3.4 & & & US & 5.6 & & \\
\hline
\end{tabular}


Table 3

Schoolbag features present compared to those considered to be important

\begin{tabular}{lccccc}
\hline & \multicolumn{2}{c}{$\begin{array}{c}\text { Schoolbag features } \\
\text { present on bag (\%) }\end{array}$} & & \multicolumn{2}{c}{$\begin{array}{c}\text { Schoolbag features considered } \\
\text { important or very important (\%) }\end{array}$} \\
\cline { 2 - 3 } \cline { 5 - 6 } Schoolbag feature & IRE & US & & IRE & US \\
\hline Padded Shoulder Straps & 92.1 & 88.7 & & 97.7 & 94.4 \\
Adjustable Shoulder Straps & 88.7 & 86.7 & & 97.4 & 97.5 \\
Compartments & 87.1 & 85.5 & & 87.0 & 91.5 \\
Padded Back & 73.3 & 51.6 & & 91.9 & 77.6 \\
Wheels & 11.3 & 2.3 & & 40.0 & 17.5 \\
Hip Strap & 13.8 & 10.5 & & 37.2 & 21.9 \\
Chest Strap & 9.3 & 19.5 & & 45.7 & 41.2 \\
\hline
\end{tabular}

Table 4

Factors of schoolbag use

\begin{tabular}{lcr}
\hline Factors of schoolbag use & IRE (\%) & US (\%) \\
\hline Method of Carriage & & \\
$\quad$ On both Shoulders & 70.9 & 90.1 \\
Wheeled & 10.6 & 5.6 \\
$\quad$ Other & 18.5 & 4.4 \\
Schoolbag Weight & & \\
$\quad$ Aware of guideline limit & 17.8 & 52.3 \\
$\quad$ Not aware of guideline limit & 82.2 & 47.7 \\
\hline
\end{tabular}

of parents considered content placement within the schoolbag important or very important $88.5 \%$ [85.5\%]. The majority of Irish parents reported that they checked their child's schoolbag daily (63.4\%) or weekly $(27.1 \%)$. A significant association was identified between the Irish child's age and sibling place and how often the schoolbag was checked. Younger children and oldest siblings were more likely to have their schoolbag checked daily $(p=0.001$ and $p=0.022$ respectively). Similar proportions of Irish and United States children were driven to school by car ( $56.7 \%$ vs $54.9 \%$ ), but more Irish children walked to school (23.9\% vs $8.2 \%$ ), and more United States children travelled to school by bus (41.4\% vs $9.3 \%)$.
There were no significant findings for the association between parental education level and awareness of schoolbag weight limit guidelines $(p=0.750$; $[p=0.453])$, the type of schoolbag owned $(p=0.642$ [ $p=0.352])$, or the method of carriage thought appropriate $(p=0.584[p=0.159])$.

\subsection{The effects of wearing a schoolbag}

The parents were asked, using open questions, if they knew of any effects of schoolbag carriage. Only $18.8 \%$ (Ire) and $33.6 \%$ (US) parents identified positive effects and $81.4 \%$ (Ire) and $49.2 \%$ (US) stated that there were negative effects associated with schoolbag carriage. Developing responsibility was the most commonly reported positive effect and back pain was identified as the most negative consequence of schoolbag carriage (Table 5). Parental awareness of potential positive effects of schoolbag carriage was significantly associated with a higher educational level for Irish parents $(p=0.017)$, but not for United States parents $(p=0.307)$. Awareness of potential negative effects of schoolbag carriage was significantly associated with a higher educational level $(p<0.001 ;[p=0.003])$.

Table 5

Reported effects of schoolbag carriage

\begin{tabular}{|c|c|c|c|c|c|c|c|}
\hline \multicolumn{8}{|c|}{ Positive Effects \% (n)* } \\
\hline & Responsibility & Strengthening & Good posture & Balance & Other & Exercise & Easy to carry \\
\hline \multicolumn{8}{|l|}{ IRE } \\
\hline $18.8 \%(83)$ & $63.9 \%(53)$ & $10.8 \%(9)$ & $8.4 \%(7)$ & $3.6 \%(3)$ & $12 \%(10)$ & $12 \%(10)$ & $0(0)$ \\
\hline \multicolumn{8}{|l|}{ US } \\
\hline $33.6 \%(86)$ & $33.7 \%(29)$ & $12.8 \%(11)$ & $14 \%(12)$ & $0(0)$ & $9.3 \%(8)$ & $0(0)$ & $30.2 \%(28)$ \\
\hline \multicolumn{8}{|c|}{ Negative Effects $\%(\mathrm{n})^{*}$} \\
\hline & Back pain & Shoulder pain & Poor posture & Neck pain & Other & Spinal deformity & Fatigue/injury \\
\hline \multicolumn{8}{|l|}{ IRE } \\
\hline $81.4 \%(358)$ & $75.1 \%(269)$ & $22 \%(79)$ & $22.9 \%(82)$ & $8.4 \%(30)$ & $15.9 \%(57)$ & $6.1 \%(22)$ & $3.4 \%(12)$ \\
\hline \multicolumn{8}{|l|}{ US } \\
\hline $49.2 \%(126)$ & $42 \%(53)$ & $19 \%(24)$ & $11.9 \%(15)$ & $7.9 \%(10)$ & $2.4 \%(3)$ & $5.6 \%(7)$ & $11.1 \%(14)$ \\
\hline
\end{tabular}

*Respondents could choose more than one option. 


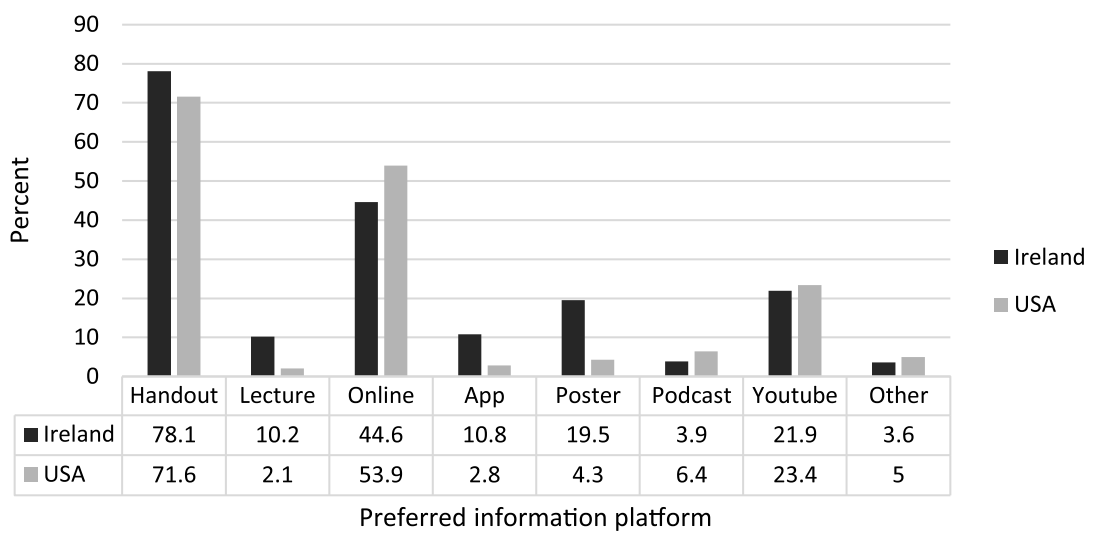

Fig. 1. Preferred platforms for receiving information $(n=313$ [141]). *Respondents could choose more than one option.

\subsection{Information}

Only 7.4\% $(n=33)$ of Irish parents and $19.5 \%$ $(n=50)$ of United States parents had ever received information on appropriate schoolbag use, most commonly through media platforms $(n=18[n=16])$, school $(n=11[n=10])$, online $(n=8[n=10])$ and other $(n=11[n=12])$. Parental educational level was not significantly associated with whether or not parents had received information ( $p=0.216[p=0.728])$.

A significantly greater proportion of Irish parents expressed interest in receiving guidance than US parents $(70.8 \%$ vs $55.1 \% ; p<0.0001)$. A handout and online were the preferred educational platforms (Fig. 1). Parental age $(<40: \geq 40$ years) was not associated with preference for a handout $(p=0.076$; $[p=0.134])$. Age was not associated with preference for online information among Irish parents $(p=0.769)$, but older US parents were significantly more likely to request online information than younger parents $(p=0.005)$.

\section{Discussion}

This study investigated parental awareness of factors related to schoolbag carriage, and made comparisons between Irish and United States parents. In keeping with the findings of previous studies [21, 22], most children owned a backpack. However despite this, fewer parents identified it as the most suitable schoolbag, suggesting that although backpacks were purchased, parental awareness was lower regarding their suitability. A minority of children owned a wheeled bag, but a greater proportion of Irish parents reported it as being the most suitable schoolbag. This finding is a cause for some concern because par- ents may perceive that wheeled bags relieve the load to be carried, but they may not be aware that the bags must be lifted using awkward postures [27] when the child is negotiating stairs and kerbs (curbs) [28]. It was also found that owning a wheeled bag was significantly associated with having a heavy bag $(\geq 10 \%$ BW) [28]. In the current study, younger Irish children were significantly more likely to own wheeled bags and older children backpacks, which may suggest that older children play a role in the schoolbag selection. This illustrates the need for parental education to aid schoolbag selection for younger children. Parents who are better informed would be able to choose a suitable bag despite the marketing strategies that may encourage them to do otherwise. Furthermore, it highlights the need for education of those involved in design, production, marketing and retailing of school bags.

A positive finding was that the majority of parents identified the ideal mode of carriage as having straps on both shoulders [29], implying adequate parental knowledge. This finding is in keeping with one previous study [23] but is in contrast to others [21, 22] who reported that awareness of method of schoolbag carriage was low. It has been identified that a lower level of education was associated with lower parental awareness of method of carriage [21], but the current study found no difference in awareness across educational levels. The proportion of parents with a third level education was significantly higher in the current study (67.3\% [86.5\%]) than in Dianat and Karimi's study (25.7\%) [21], and this may account for the discrepancy between the two findings. A further positive finding was that parental awareness of the importance of specific schoolbag features was excellent, and consistent with the findings of others [20, 
23]. The hip strap was the exception with only $37.2 \%$ and $21.9 \%$ of Irish and United States parents aware of its importance, similar to previous observations [22, 23]. Although considered important for backpacks worn by adults [30] as it helps to distribute the load, it appears that the hip strap is not thought to be an important schoolbag feature.

Parental interest and involvement in their child's schoolbag use has been proposed as a strategy to reduce the loads carried by children $[19,21]$ and to promote safe and optimum schoolbag carriage [20]. It has been found previously that parental involvement in monitoring the schoolbag contents of 6-12 year olds was low [19, 22]. However, in stark contrast only $1.1 \%$ of Irish parents in this study had never checked the contents, with $90.5 \%$ checking the contents at least once a week. Younger children were significantly more likely to have their schoolbag checked by a parent, which is an expected finding as their level of parental dependence would be higher than that of older children. This association was not tested in previous studies and therefore no comparisons could be made.

Notwithstanding the limited scientific evidence, the European schoolbag load limit is up to $10 \%$ of the child's bodyweight [1]. As the standard European recommendation, it could be assumed that parents would be informed, but only $17.8 \%$ of Irish parents selected this response. A significantly greater proportion of the United States parents (52.3\%) chose a correct response. Both groups of parents were presented with the same eight possible response options, however only one answer $(<10 \% \mathrm{BW})$ was correct for Irish parents, whereas the United States parents could choose from one of 3 correct answers $(<10 \%$, $<15 \%,<20 \% \mathrm{BW}$ ) as all were in keeping with various United States guideline schoolbag weights [6-8]. The proportion of Irish parents who choose the correct load limit was also considerably lower than parents in any other study [20-23]. However the number of response options was greater in the current study than in previous studies, making it more difficult for the participants to identify the correct answer. Awareness of the United States parents in this study was in keeping with others $[20,21]$ and was considered to be generally low. In other studies, good awareness of schoolbag weight has been demonstrated $[22,23]$. However, the fact that the guideline weight limits are not supported in the literature raises the bigger question of why they persist as part of the guidelines for schoolbag carriage. Schoolbag weight limits that are based on a percentage of the child's bodyweight are unfounded $[10,31,32]$ and therefore should be removed from guidelines disseminated to parents. Advice from academics, health promotion units and professional organizations should be evidence-based and include the broader factors such as schoolbag type, features and method of carriage, with less emphasis on the schoolbag weight.

Parents were largely unaware that there may be positive effects of schoolbag carriage. Carrying a schoolbag is a form of regular physical activity and as such could have some positive health benefits for the child, yet few Irish and no United States parents identified schoolbag carriage as exercise. Parents with a lower education level were less aware of positive and negative effects of schoolbag carriage, suggesting the need for better education on the benefits and consequences of schoolbag carriage. This was consistent with Dianat and Karimi who also found an association between awareness of schoolbag use and parental level of education [21]. A greater proportion of parents stated that schoolbag carriage could have a negative effect on their child. Back pain $(75.1 \%)$ was more frequently cited as a negative consequence than shoulder pain $(22 \%)$. It is interesting that there was a much greater perceived association between schoolbag carriage and back pain, as it has been found that schoolbag-related discomfort was more often reported in the shoulders than in the back [12, $31,33]$. Although not investigated in the study, the effects of schoolbag carriage could be influenced by adherence to ergonomic principles such as the correct adjustment of the shoulder straps.

The majority of parents had never received information on schoolbags, and more Irish parents than United States expressed an interest in receiving information on schoolbag carriage. An interesting finding was that despite living in a technological society, the majority of parents chose a handout as the preferred platform for receiving information, followed by online information. With the predominant age range of parents 30-49 years, it was speculated that parents would choose an online source and that there would be an age-related difference in the preference. However, parental age and the preferred platform for receiving information were mostly unrelated. The parents stated that they would like more information, but given that their level of schoolbag awareness was satisfactory, this may not be necessary. Additionally, it has been shown that increasing knowledge alone does not always improve adherence [34]. It is also acknowledged that it is difficult to give advice about preventive strategies because the immediate benefi- 
cial effects are not obvious [14]. The current study did not investigate schoolbag-related behavior of the children, but it has been shown that the level of parental awareness about schoolbags was not reflected in the child's behavioral practice [22, 23].

Although purposive sampling was used to ensure a representative sample of the population, the homogeneity of the demographic characteristics of the participants may have affected the results. It is possible that the low United States response rate and responder bias contributed to these sample characteristics. The sample may therefore not be representative and the results may not be extrapolated to the general population. A further limitation is the cross-sectional study design, as causal inferences cannot be made.

\section{Conclusion}

Despite gaps identified, Irish and US parents have satisfactory knowledge of appropriate schoolbag type and carriage. However, there is an overall poor level of knowledge translation from professional organizations to the key stakeholders, such as parents, as they were not identified as a source of acquired information. A significant proportion of Irish parents considered a wheeled bag to be the optimum type of bag for their child and the exact sources of this advice are unknown. Channels for the dissemination of evidence-based information, tailored to suit the understanding of all parents, should be established, as there remains a need for education through credible sources. The information should also be distributed to other stakeholders such as schoolbag designers, manufacturers, marketing and retailing personnel in order to promote the availability and preference of the optimum bag choice. Informed teachers also have a role to play as they may influence parents' bag choice. In this study, the parents' demand for further information was high, and the ideal platforms, such as handouts or online, were identified. Parental awareness of schoolbag carriage, although satisfactory, could be enhanced through continuing to emphasise the broad ergonomic principles of schoolbag carriage such as type, features and their optimum use, with less emphasis on schoolbag weight alone.

\section{Acknowledgments}

The authors are grateful to the parents who participated and to the children, school teachers and principals for their co-operation.

\section{Conflict of interest}

\author{
None to report.
}

\section{References}

[1] Voll HJ, Klimt F. Strain in Children Caused by Carrying Schoolbags. Offentl Gesundh Wes 1977;39(7):369-378.

[2] Cottalorda J, Rahmani A, Diop M, Gautheron V, Ebermeyer $\mathrm{E}, \mathrm{Belli} \mathrm{A}$. Influence of school bag carrying on gait kinetics. J Pediatr Orthop B 2003;12(6):357-364.

[3] van Gent C, Dols JJ, de Rover CM, Hira Sing RA, de Vet HC. The weight of schoolbags and the occurrence of neck, shoulder, and back pain in young adolescents. Spine (Phila Pa 1976). 2003;28(9):916-921.

[4] Skaggs DL, Early SD, D’Ambra P, Tolo VT, Kay RM. Back pain and backpacks in school children. J Pediatr Orthop 2006;26(3):358-363.

[5] Education Queensland; 2014. [cited 2014 Oct 08]. Available from: http://education.qld.gov.au/health/pdfs/healthsafe

[6] American Occupational Therapy Association; 2014. [cited 2014 Apr 25]. Available from: http://www.aota.org.

[7] American Physical Therapy Association; 2014 [cited 2014 Apr 25]. Available from: http://www.apta.org

[8] American Academy of Pediatrics; 2014 [cited 2014 Apr 25]. Available from: https://www.aap.org

[9] Dockrell S, Simms C, Blake C. Schoolbag weight limit: Can it be defined? J Sch Health 2013;83(5):368-377.

[10] Lindstrom-Hazel D. The backpack problem is evident but the solution is less obvious. Work 2009;32(3):329-338.

[11] Sheir-Neiss GI, Kruse RW, Rahman T, Jacobson LP, Pelli JA. The association of backpack use and back pain in adolescents. Spine (Phila Pa 1976) 2003;28(9):922-930.

[12] Moore MJ, White GL, Moore DL. Association of relative backpack weight with reported pain, pain sites, medical utilization, and lost school time in children and adolescents. J Sch Health 2007;77(5):232-239.

[13] Kellis E, Emmanouilidou M. The effects of age and gender on the weight and use of schoolbags. Pediatr Phys Ther 2010;22(1):17-25.

[14] Rapoff MA. Management of adherence and chronic rheumatic disease in children and adolescents. Best Pract Res Cl Rh 2006;20(2):301-314.

[15] Van Hecke A, Grypdonck M, Defloor T. A review of why patients with leg ulcers do not adhere to treatment. J Clin Nurs 2009;18(3):337-349.

[16] Kim JH, Kim GS, Kim EJ, Park S, Chung N, Chu SH. Factors affecting medication adherence and anticoagulation control in Korean patients taking warfarin. J Cardiovasc Nurs 2011;26(6):466-474.

[17] Cochrane GM, Horne R, Chanez P. Compliance in asthma. Resp Med 1999;93(11):763-769.

[18] Dockrell S, Simms C, Blake C. Guidelines on schoolbag use: Messaging to inform the stakeholders. Work 2016;54(2):489-492.

[19] Forjuoh SN, Little D, Schuchmann JA, Lane BL. Parental knowledge of school backpack weight and contents. Arch Dis Child 2003;88(1):18-19.

[20] Javadivala Z, Allahverdipour H, Dianat I, Bazargan M. Awareness of parents about characteristics of a healthy school backpack. Health Promot Perspect 2012;2(2): 166-172. 
[21] Dianat I, Karimi MA. Association of parental awareness of using schoolbags with musculoskeletal symptoms and carrying habits of schoolchildren. J Sch Nurs 2014;30(6):440-447.

[22] Magrabi NME, Mahmoud SRM, Yousef YE. Awareness of parents about school backpack and its related musculoskeletal disorders in Assiut City. J Nurs Health Sci 2015;4(6):5-11.

[23] Patil MA, Sumana S, Shagale N. Awareness of parents about characteristics and carrying habits of backpacks and its comparison with behavioural practices of their children. Int $\mathbf{J}$ Pediat Res 2016;3(3):173-179.

[24] Grimshaw JM, Eccles MP, Lavis JN, Hill SJ, Squires JE. Knowledge translation of research findings. Implement Sci 2012;7:50.

[25] Fluid Surveys; 2016 [cited 2016 Jan 10]. Available from: http://www.fluidsurveys.com

[26] Pallant J. SPSS survival manual: A step by step guide to data analysis using SPSS for Windows, 3rd ed. Maidenhead: Open University Press; 2007.

[27] Geller RJ, Rubin IL, Nodvin JT, Teaque WG, Frumkin H. Safe and Healthy School Environments. Pediatr Clin Am 2007;54(2):351-373.

[28] Forjuoh SN. School backpack weights: A survey of students in Ghana, Guatemala and the USA. Inj Control Saf Promot 2004;11(4):287-289.
[29] Korovessis P, Koureas G, Zacharatos S, Papazisis Z. Backpacks, back pain, sagittal spinal curves and trunk alignment in adolescents: A logistic and multinomial logistic analysis. Spine (Phila Pa 1976) 2005;30(2):247-255.

[30] Sharpe SR, Holt KG, Saltzman E, Wagenaar RC. Effects of a hip belt on transverse plane trunk coordination and stability during load carriage. J Biomech 2008;41(5):968-976.

[31] Dockrell S, Simms C, Blake C. Schoolbag carriage and schoolbag-related musculoskeletal discomfort among primary school children. Appl Ergon 2015;51:281-290.

[32] Dianat I, Sorkhi N, Pourhossein A, Alipour A, AsghariJafarabadi M. Neck, shoulder and low back pain in secondary schoolchildren in relation to schoolbag carriage: Should the recommended weight limits be gender-specific? Appl Ergon 2014;45(3):437-442.

[33] Dianat I, Javadivala Z, Asghari-Jafarabadi M, Asl Hashemi A, Haslegrave CM. The use of schoolbags and musculoskeletal symptoms among primary school children: Are the recommended weight limits adequate? Ergonomics 2013;56(1):79-89.

[34] Borrelli B, Riekert KA, Weinstein A, Rathier L. Brief motivational interviewing as a clinical strategy to promote asthma medication adherence. J Allergy Clin Immun 2007;120(5):1023-1030 